\title{
Correction to: Characteristics of therapeutic alliance in musculoskeletal physiotherapy and occupational therapy practice: a scoping review of the literature
}

Folarin Babatunde ${ }^{1 *}$, Joy MacDermid ${ }^{1,2,3}$ and Norma Maclntyre ${ }^{1}$

\section{Correction}

Following publication of the original article [1], an erratum was initiated in order to include supplementary material that was not updated and not included during the online submission of the authors' corrections. The additional corrections, included below, are to Appendix II.

The original article has been corrected.

\begin{abstract}
Author details
'School of rehabilitation Science, McMaster University, 1400 Main Street West, Hamilton, ON L8S 1C7, Canada. ${ }^{2}$ Hand and Upper Limb Centre, St Joseph Hospital, London, ON, Canada. ${ }^{3}$ Department of Physical Therapy, University of Western Ontario, London, ON, Canada.
\end{abstract}

Received: 16 August 2017 Accepted: 4 December 2017

Published online: 12 December 2017

\section{Reference}

1. Babatunde F, MacDermid J, MacIntyre N. Characteristics of therapeutic

alliance in musculoskeletal physiotherapy and occupational therapy

practice: a scoping review of the literature. BMC Health Serv Res. 2017;17:

375. doi:10.1186/s12913-017-2311-3.

\footnotetext{
*Correspondence: babatufo@mcmaster.ca; folarin@doctor.com

${ }^{1}$ School of rehabilitation Science, McMaster University, 1400 Main Street

West, Hamilton, ON L8S 1C7, Canada

Full list of author information is available at the end of the article
} 


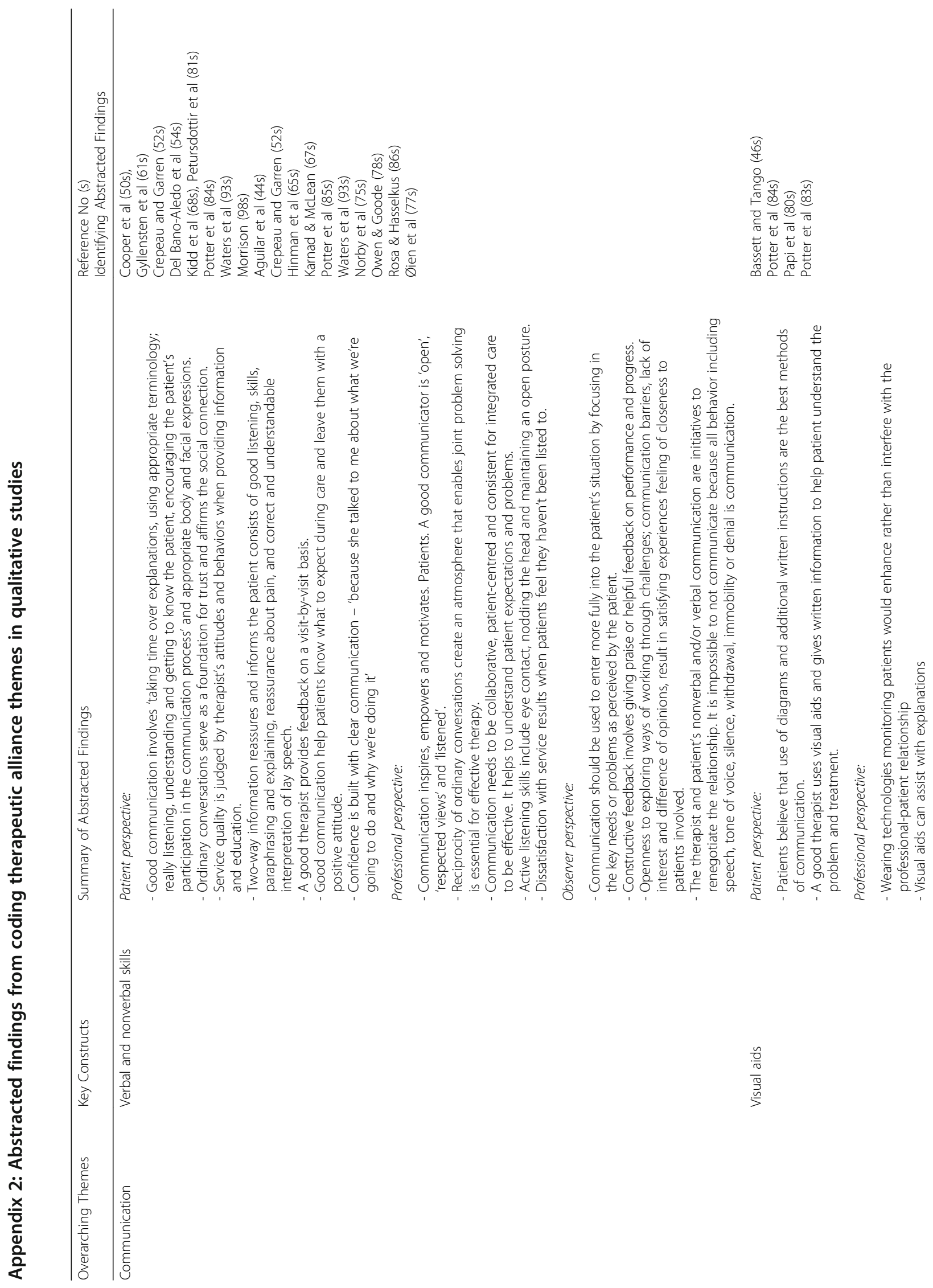




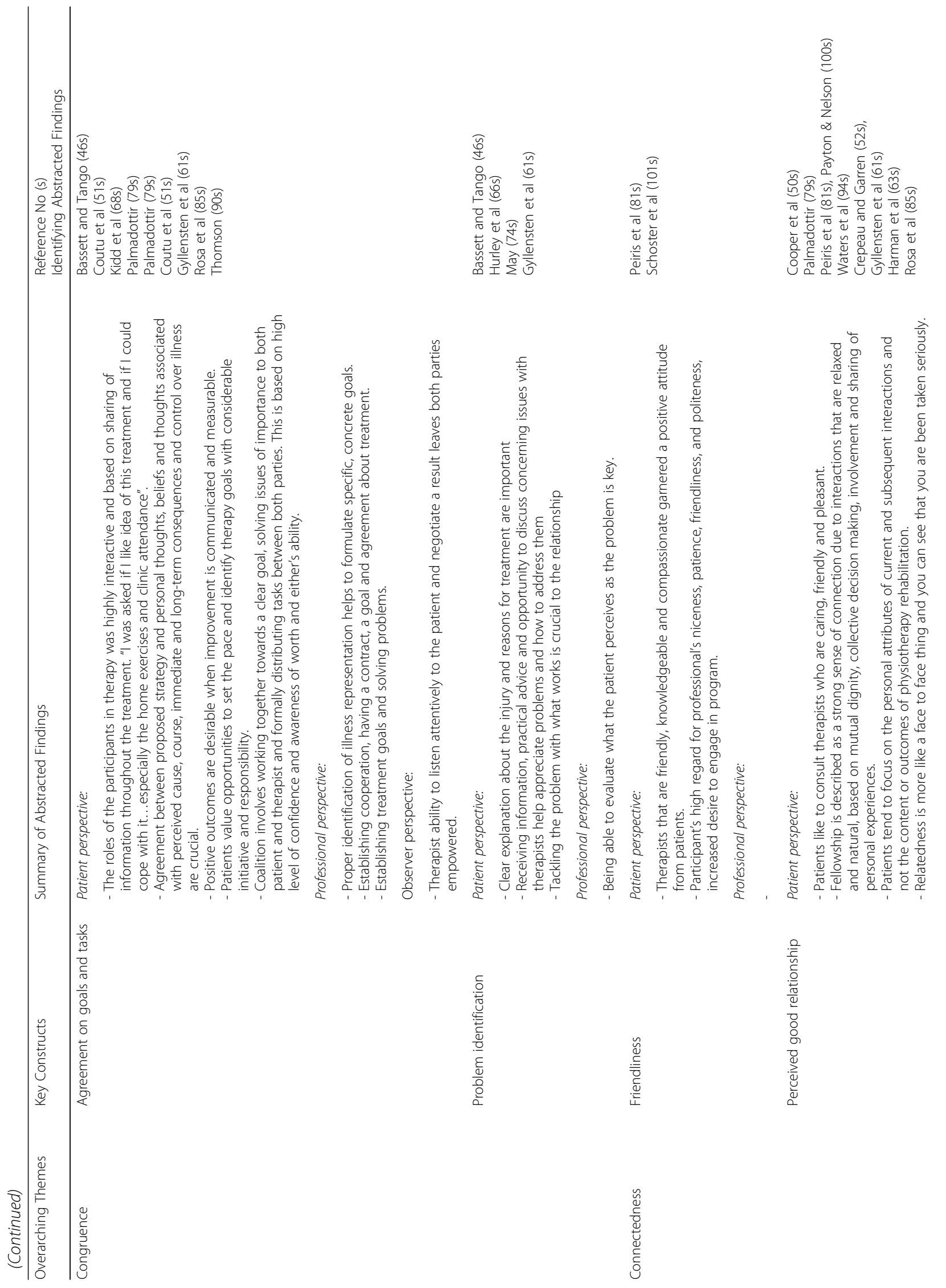



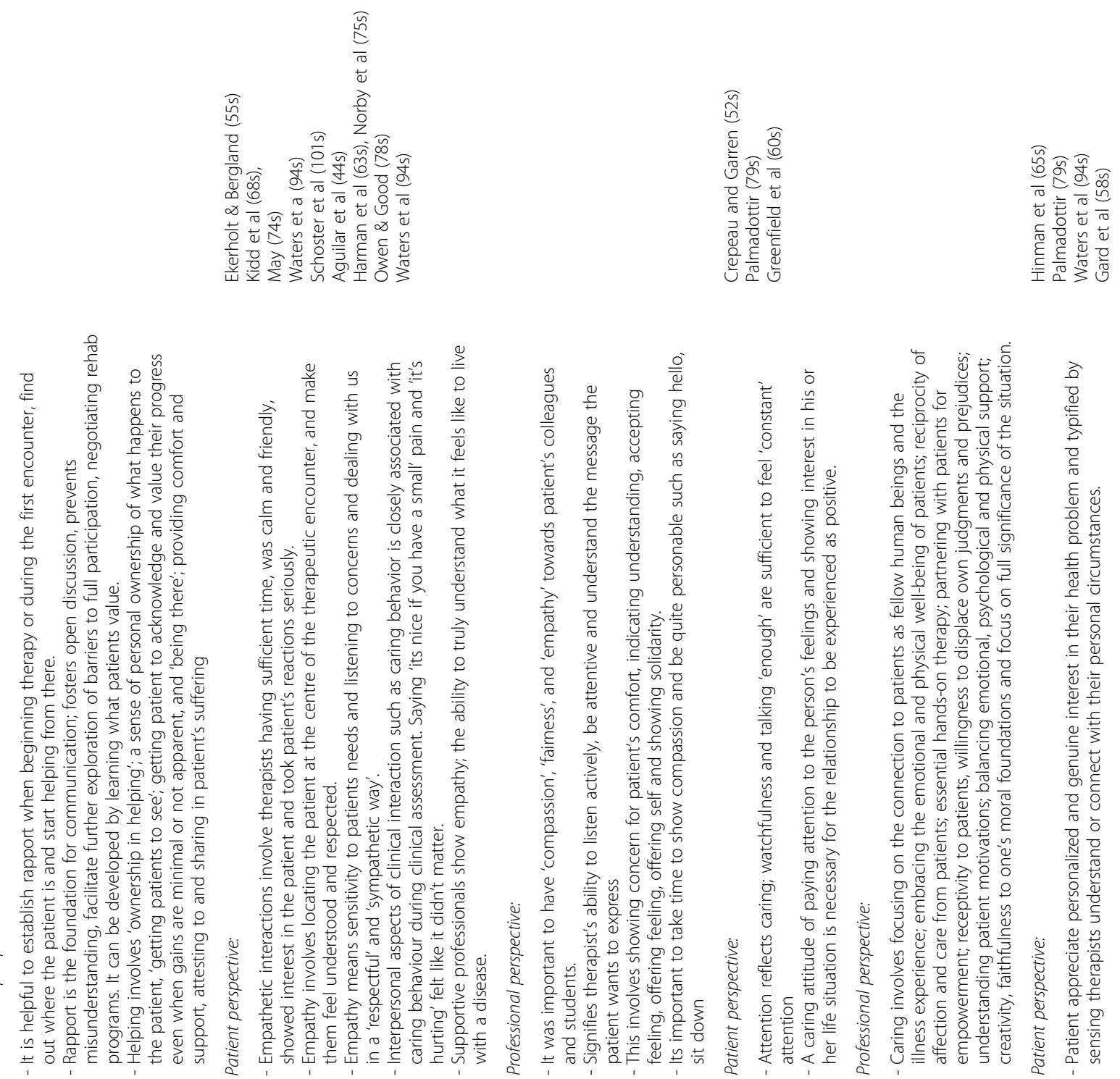

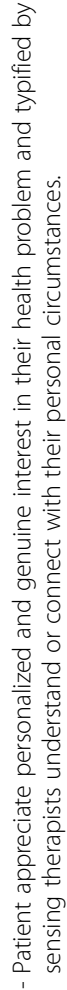

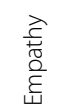

产

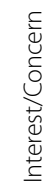




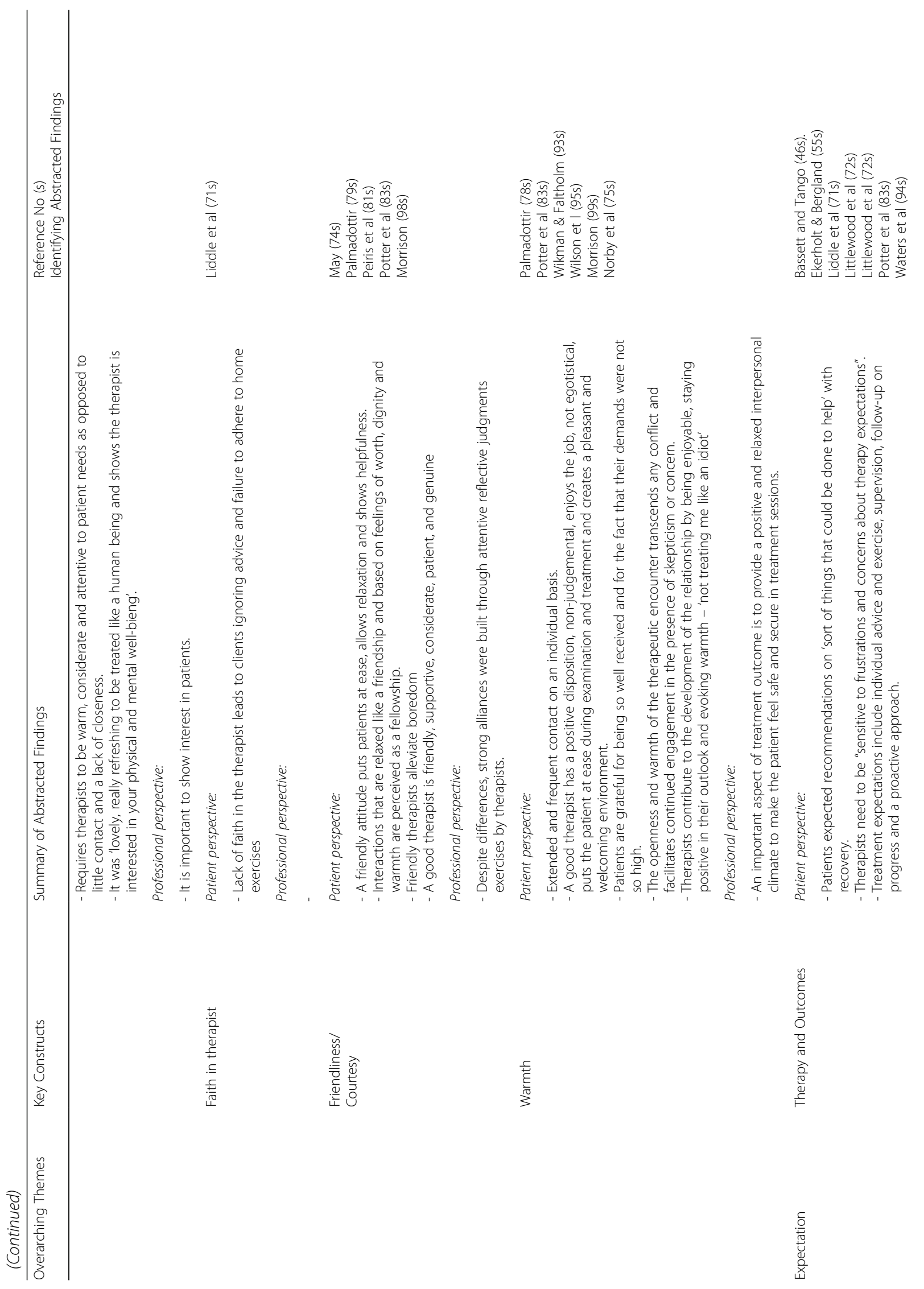




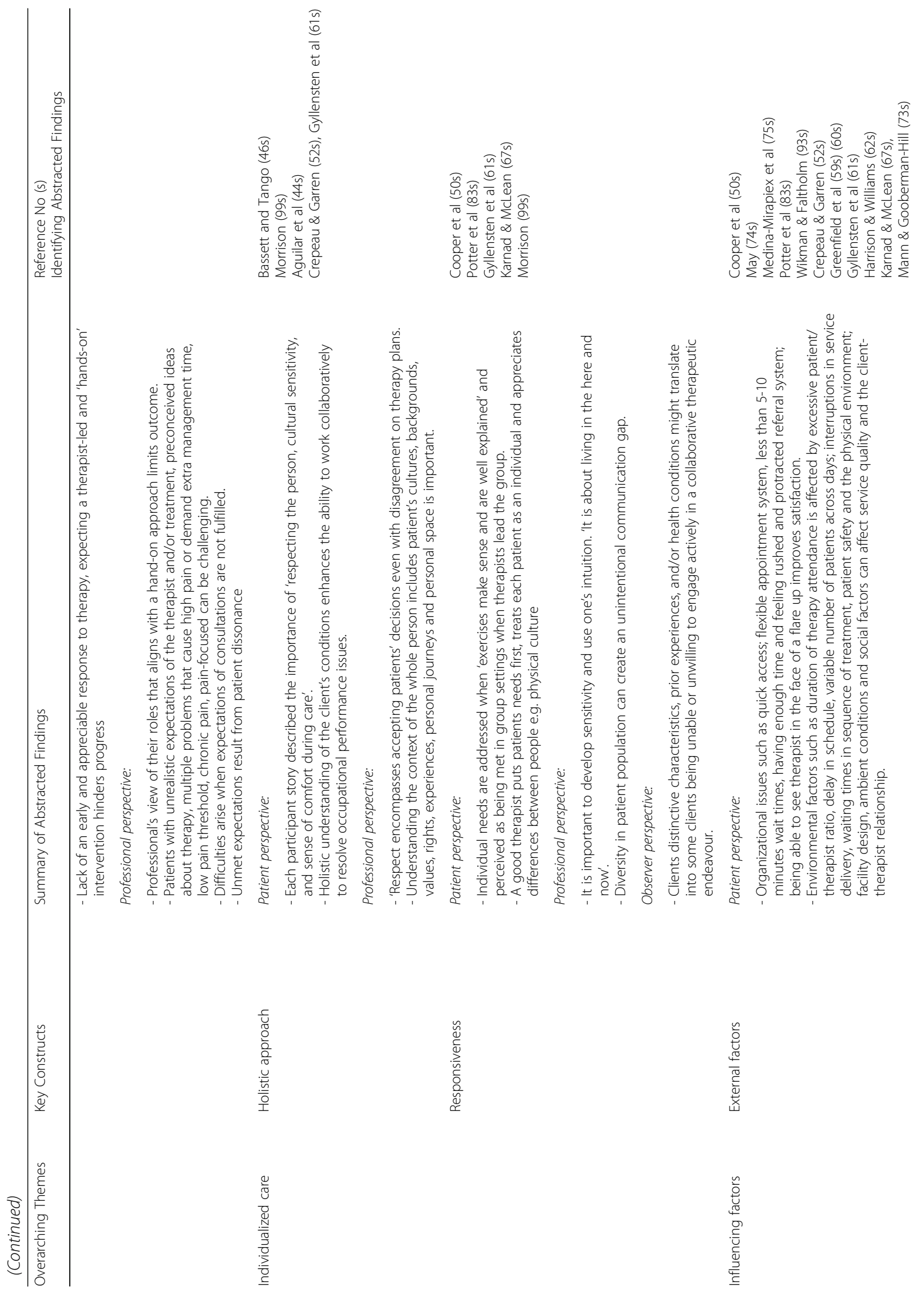




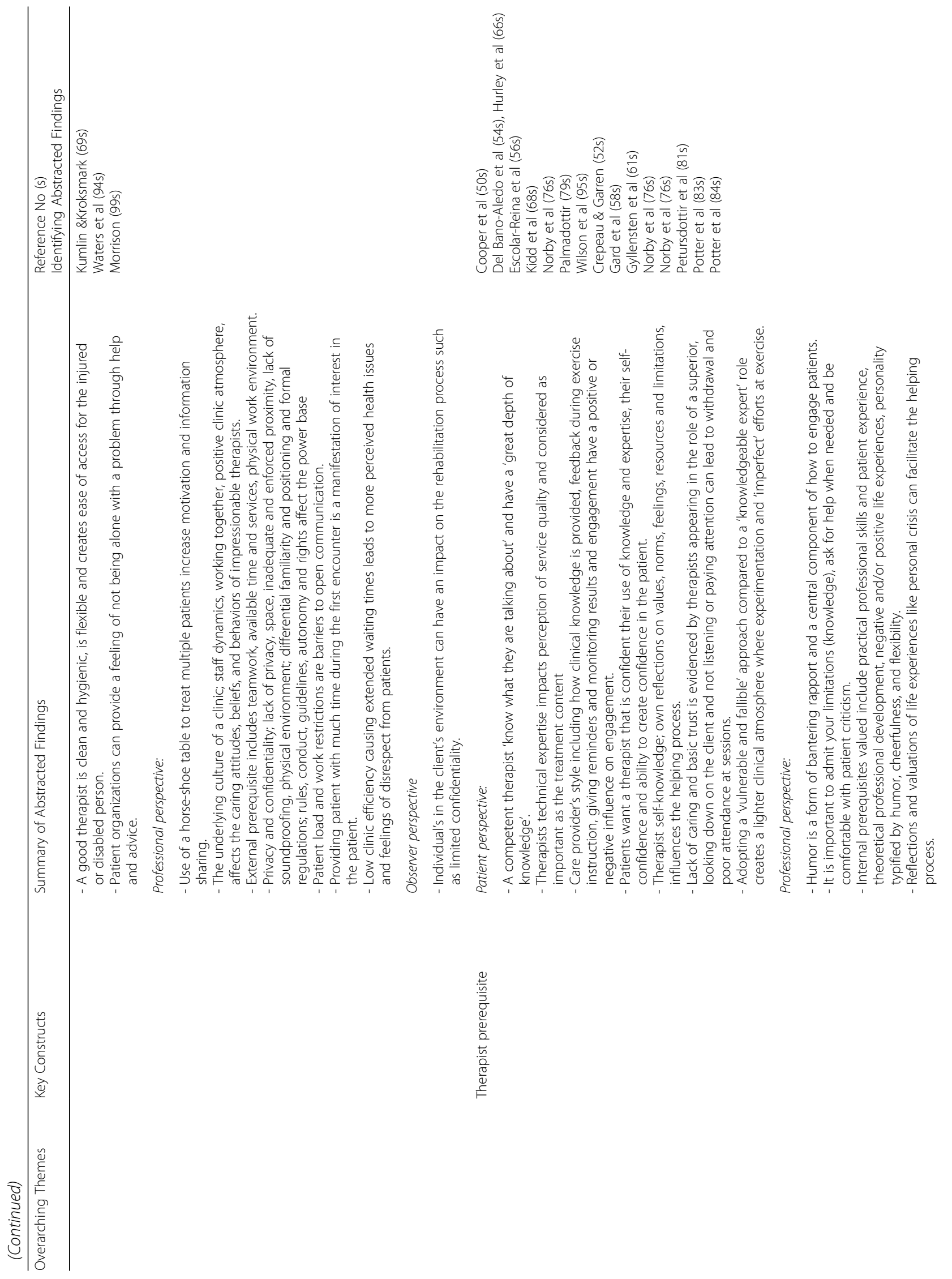



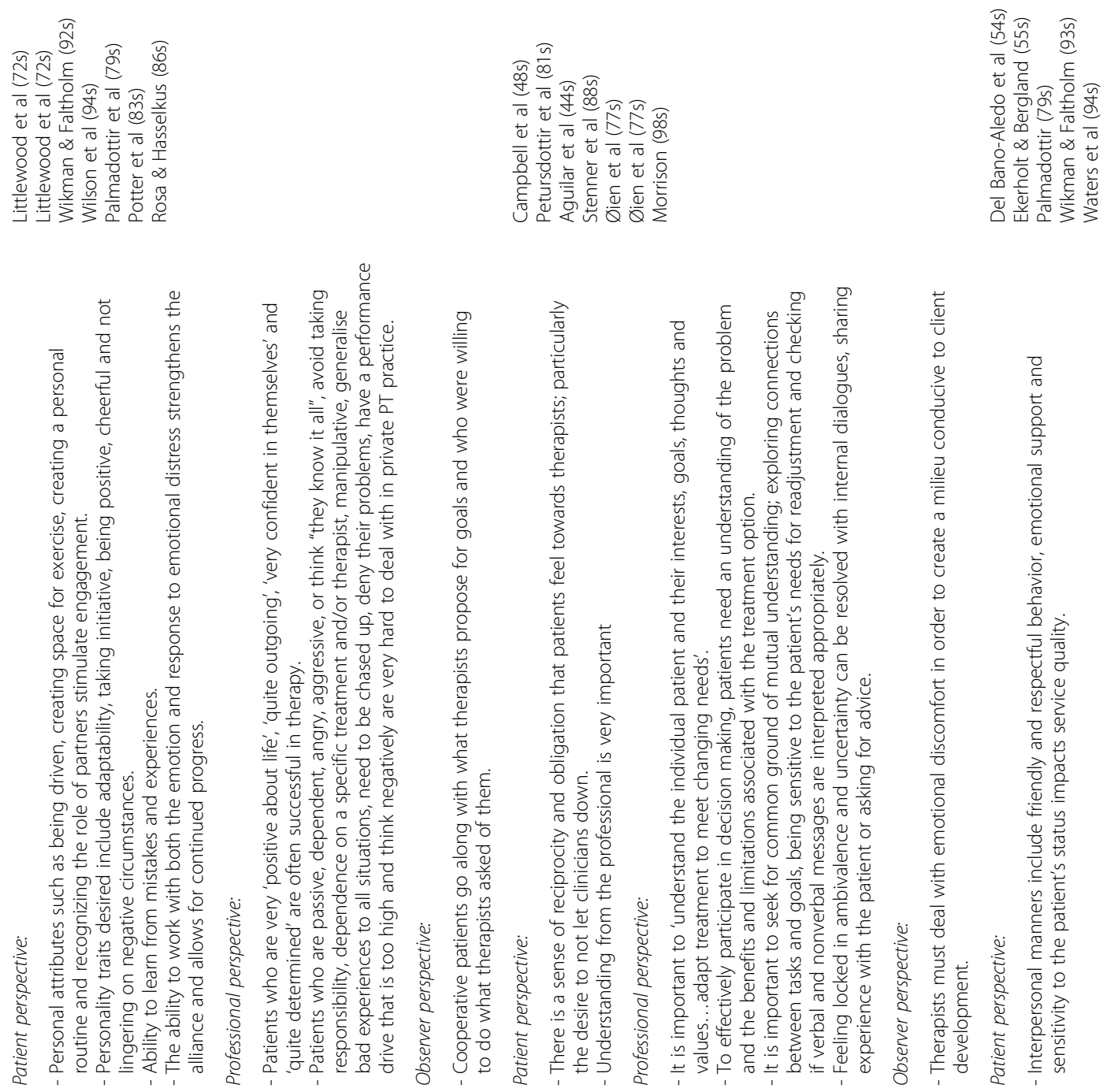

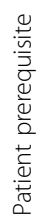

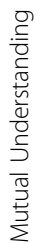

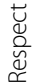




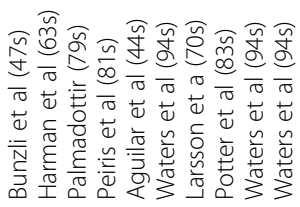

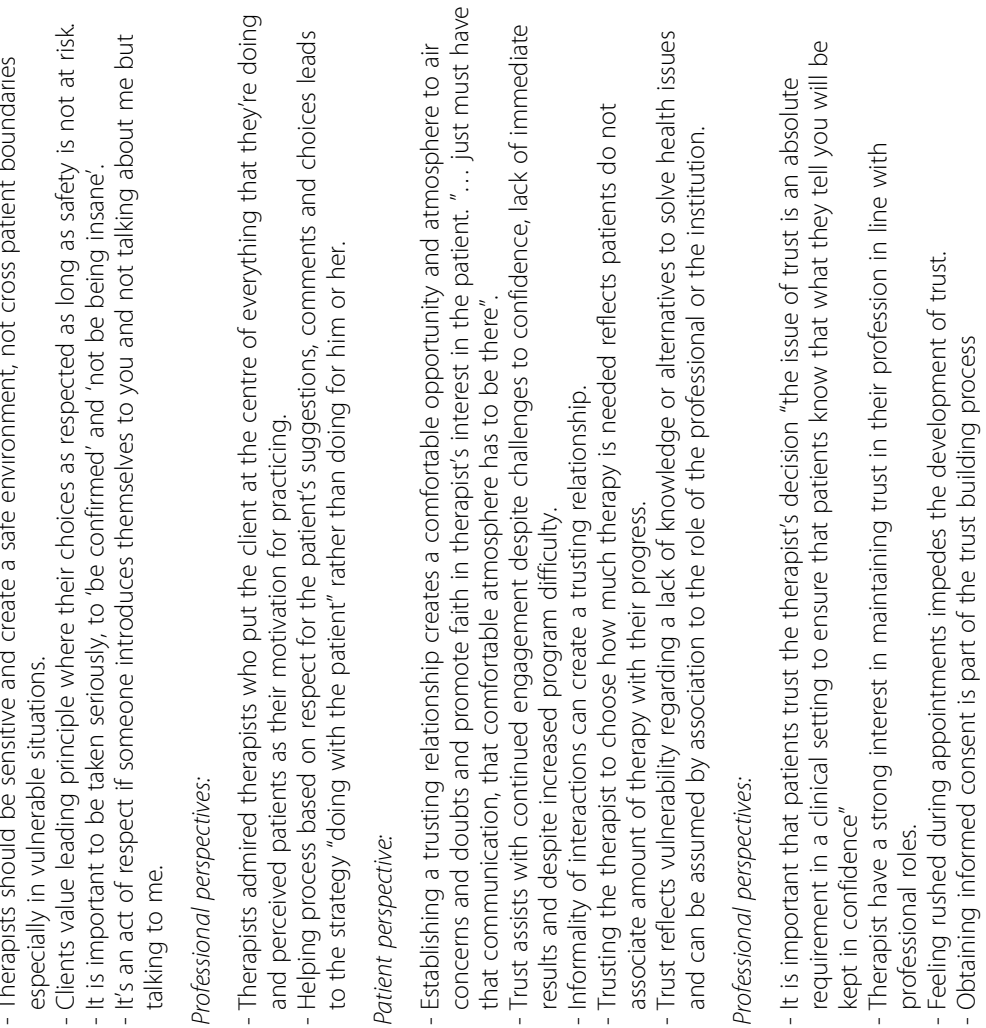

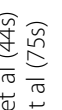

흘

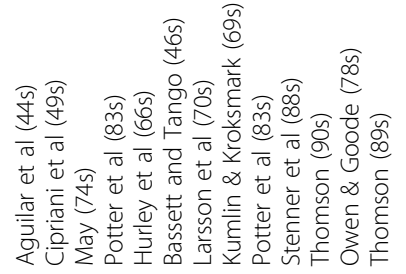



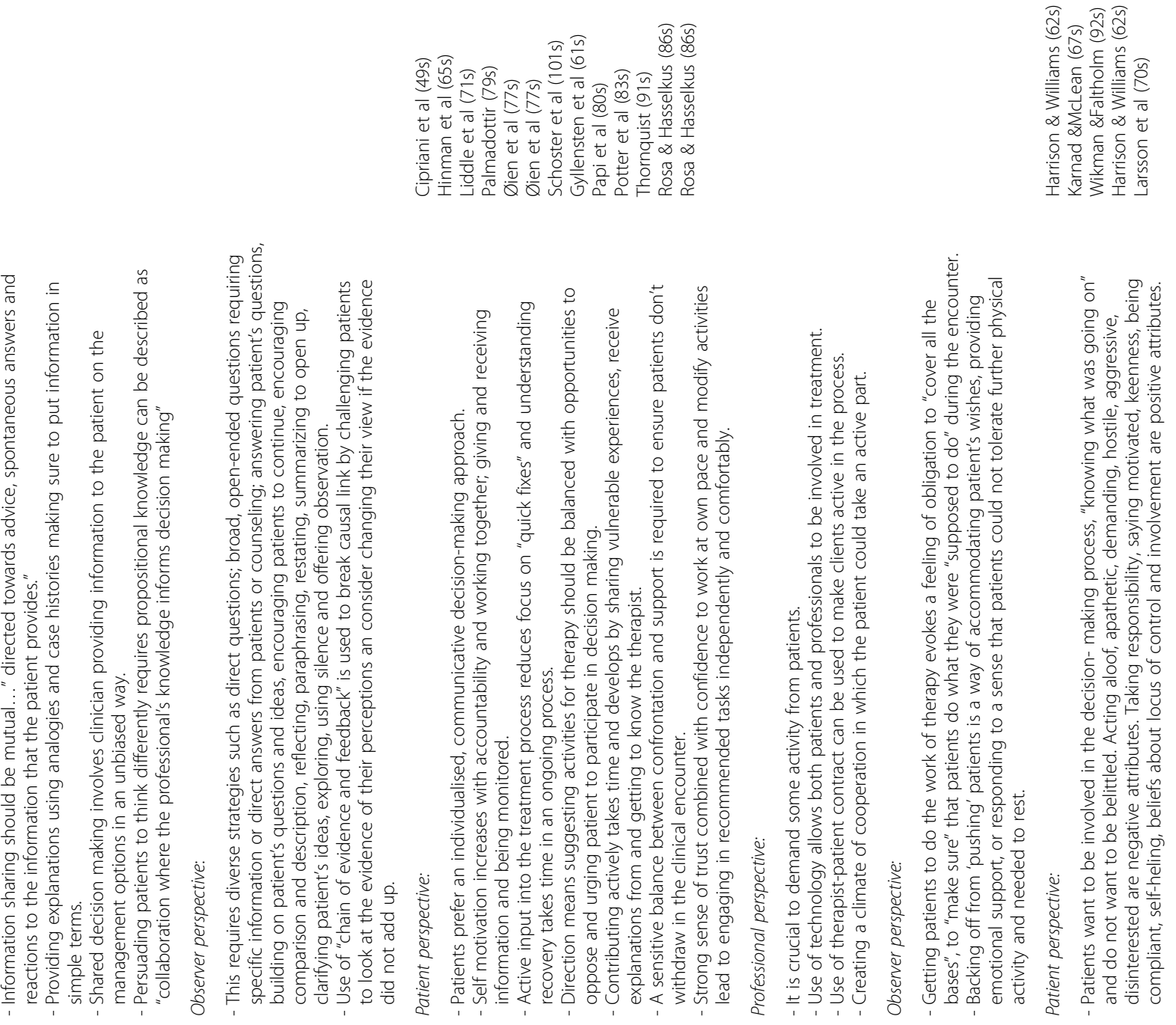

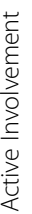




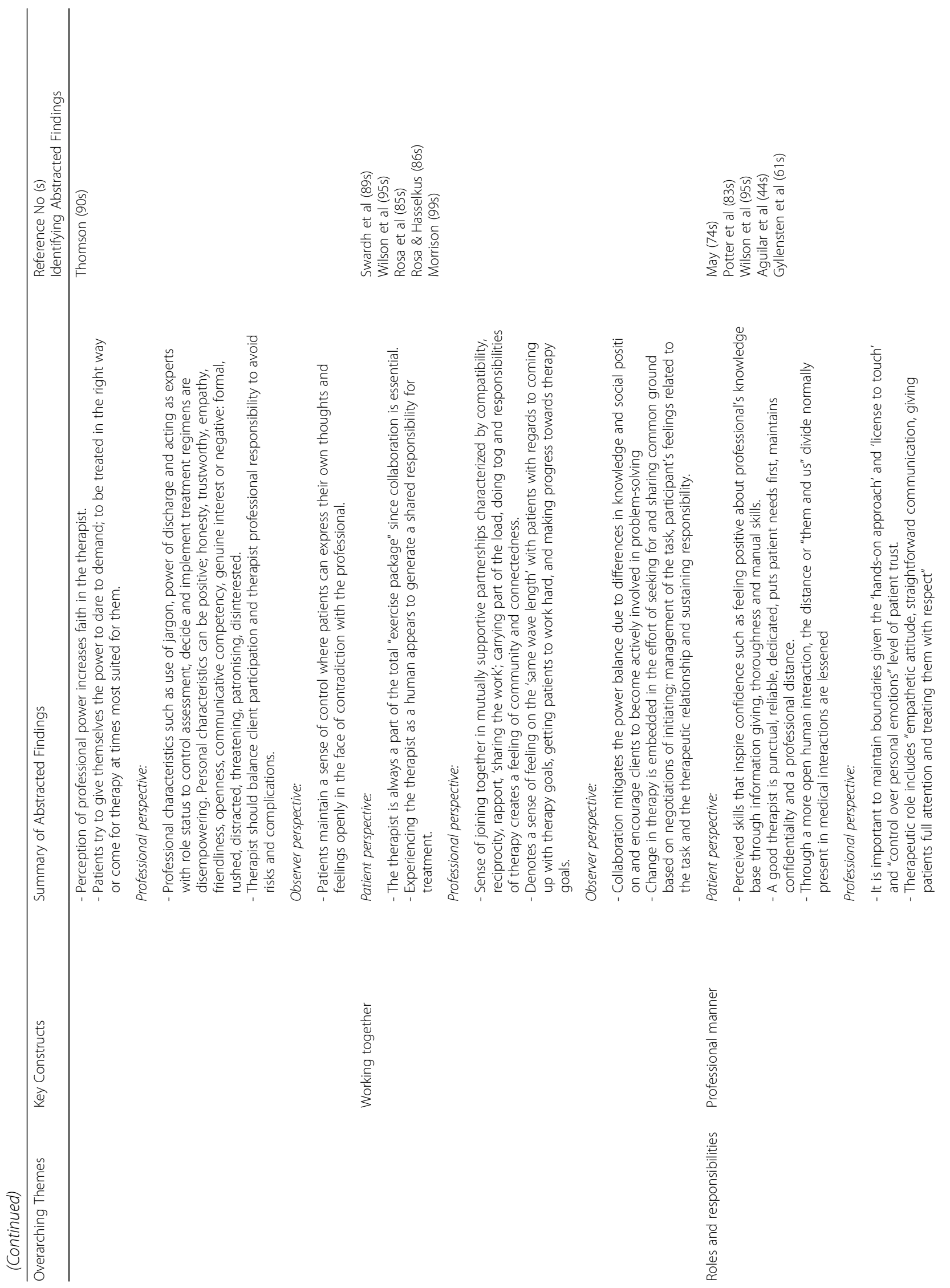




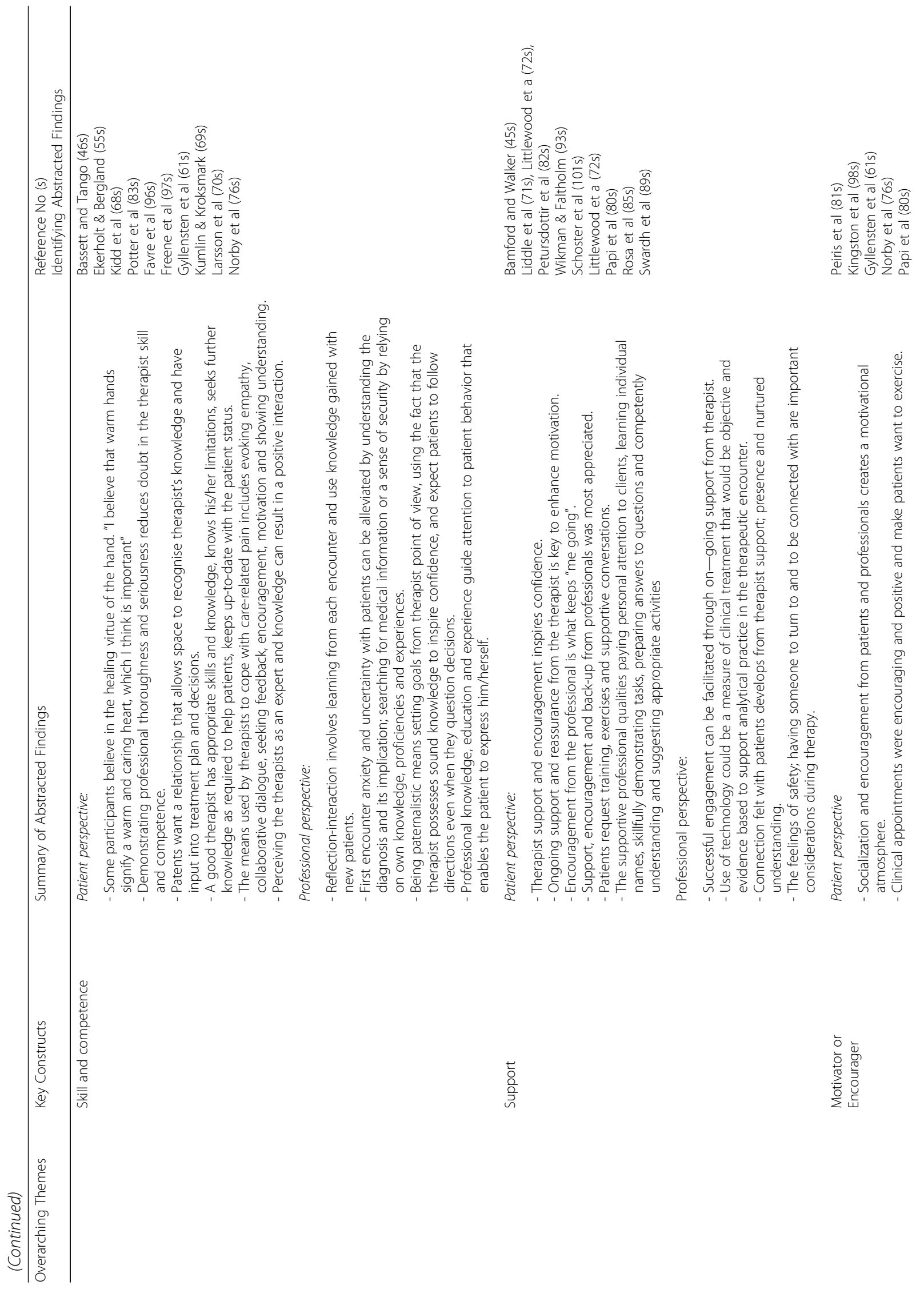




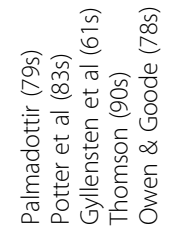

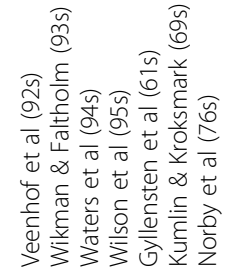

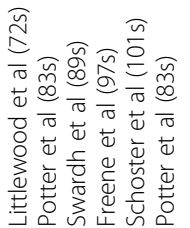

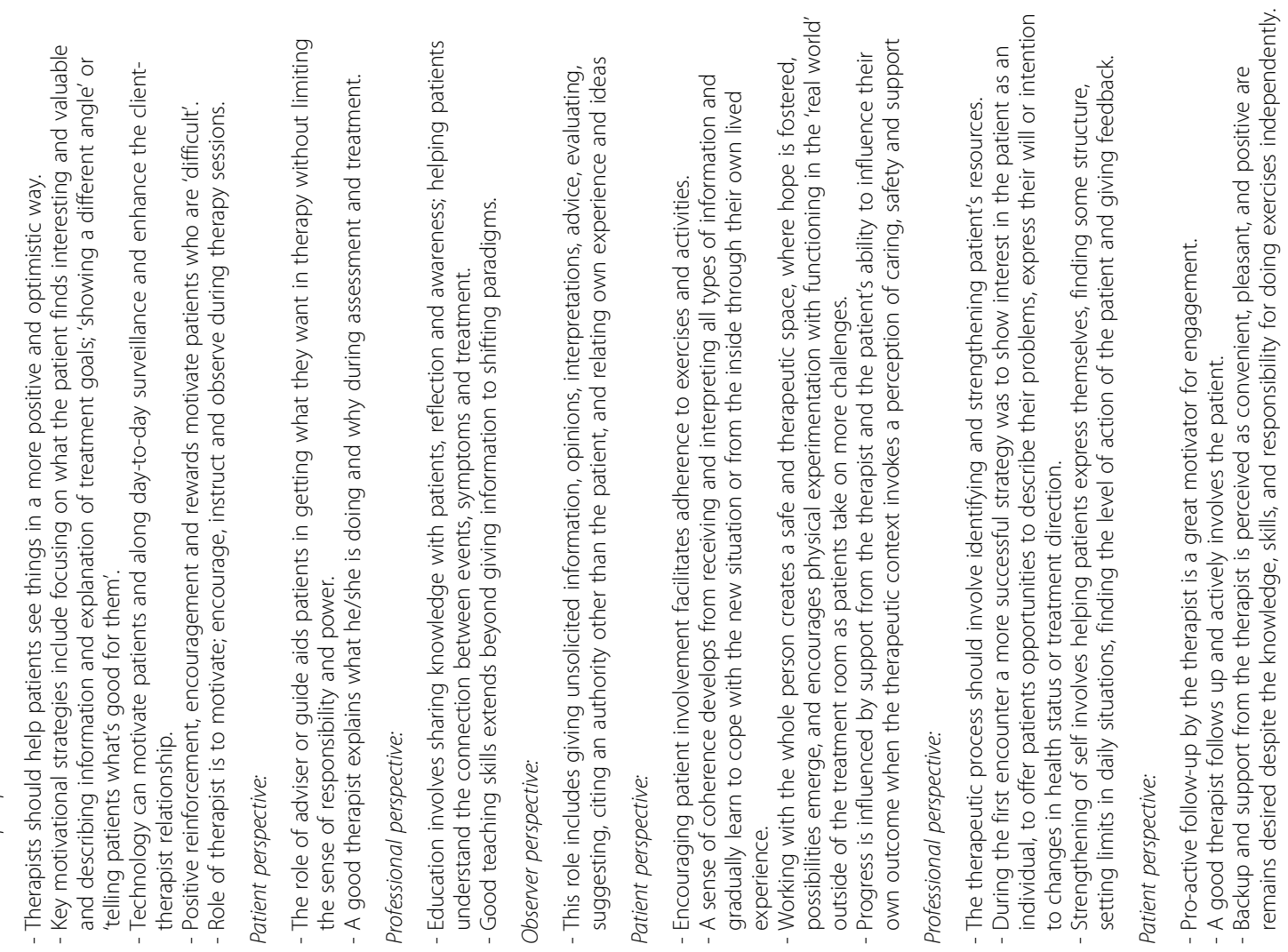

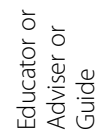

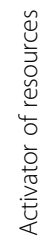

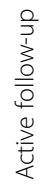




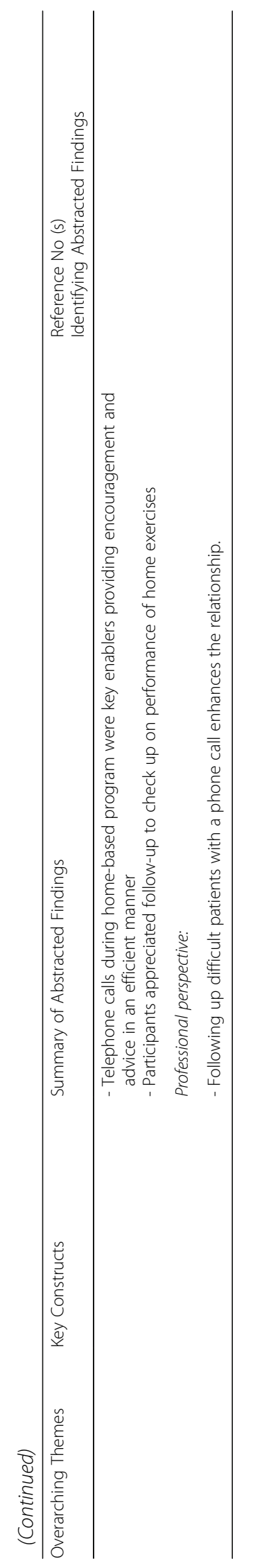

